\title{
Compact arrayed waveguide gratings for visible wavelengths based on silicon nitride
}

\author{
Syed Ashar Ali and Sang Jeen Hong \\ Department of Electronics Engineering \& MPEES, Myongji University, Korea, \\ samhong@mju.ac.kr
}

Received: 17.09 .2017

\begin{abstract}
We present two arrayed silicon-nitride-cored waveguide gratings (AWGs) that operate in a broad visible-wavelength range $(400-800 \mathrm{~nm})$, with the central wavelength $777 \mathrm{~nm}$. Our $\mathrm{Si}_{3} \mathrm{~N}_{4}$-cored AWGs are designed to satisfy single-mode waveguide characteristics. They reveal a typical propagation loss $0.1 \mathrm{~dB} / \mathrm{cm}$ and a bending loss $0.1 \mathrm{~dB}$ at the bending angle $90^{\circ}$. One of our AWGs provides five wavelength channels with the bandwidth $15 \mathrm{~nm}$ at level of $3 \mathrm{~dB}$, while the other is suited for eight wavelength channels with an improved $3 \mathrm{~dB}$ bandwidth amounting to $4 \mathrm{~nm}$. The insertion losses for the both AWGs at the peak of the transmission spectrum are equal to $7.56 \mathrm{~dB} / \mathrm{cm}$. Moreover, our AWGs reveal good spectral characteristics and small enough sizes $\left(0.02\right.$ and $0.20 \mathrm{~mm}^{2}$ for the five- and eightchannel AWGs, respectively).
\end{abstract}

Key words: arrayed waveguide gratings, silicon-nitride waveguides, waveguides for the visible wavelengths

PACS: $42.82 . \mathrm{Et}$

UDC: 535

\section{Introduction}

Arrayed waveguide gratings (AWGs) play an important role in integrated photonic circuits because of their compactness, excellent optical characteristics, high stability and mass productivity. Once they have been used solely in wavelength-division multiplexed communication networks [1, 2]. In the course of time, their spectacular characteristics have expanded their application domain to spectroscopy and chemical sensors [3-7]. Many research groups have reported implementation of the AWGs on various platforms, such as silicon-on-insulator, silica-on-silicon and silicon-based polymers [8-10]. Nonetheless, many spectroscopic applications of these materials suffer from limitations associated with optical wavelength, index contrast, as well as design and fabrication costs. One should realize in this respect that the spectroscopy of various biochemical samples is mostly based on a shorter-wavelength range, including a visible-light one. As a result, the AWG materials for different sensor applications need to be transparent at these wavelengths. Additionally, high index-contrast materials are required to allow tight bending at minimal optical losses, under the condition of compact design. Finally, the costs of the fabrication process and the material itself also represent important factors in designing the AWGs.

Although silicon reveals a high index contrast suitable for integrated photonic circuits, its optical transmission is vulnerable to fabrication errors, e.g. sidewall roughness and layer misalignment. In addition, silicon manifests a poor optical transmission below the light-source wavelength $1.1 \mu \mathrm{m}$. Therefore, it cannot be regarded as a good candidate for the visible and nearinfrared wavelength ranges $[11,12]$. Silica is a well-known low index-contrast material with high optical transparency. It can be produced using the conventional fabrication techniques typical for

Ukr. J. Phys. Opt. 2017, Volume 18, Issue 4 
microelectronic. As a consequence, silica-based devices have been reported for the visible range, which reveal excellent spectral characteristics. On the other hand, their relatively large footprints and high fabrication costs are among serious remaining problems [13].

Polymer-based AWGs have also been suggested for low-cost disposable biochips. They are characterized by ease of fabrication, high performance parameters, low optical losses and small birefringence. In particular, polydimethylsiloxane is a leading polymeric material for many lab-on-a-chip applications, exhibiting an excellent optical transparency at visible wavelengths [14]. However, it still fails to meet the requirements of high index contrast and ultracompact design [15].

To alleviate this problem, in the present work we report on compactly designed AWGs operating in a wide visible spectral range, from 400 to $800 \mathrm{~nm}$. Our AWGs are based on a singlemode low-loss $\mathrm{Si}_{3} \mathrm{~N}_{4}$ waveguide, which has been reported in Ref. [16]. The waveguide is suited for the visible wavelengths and manifests a typical propagation loss as small as $0.1 \mathrm{~dB} / \mathrm{cm}$. Recently $\mathrm{Si}_{3} \mathrm{~N}_{4}$ has appeared to become a real alternative to the optical materials mentioned above. To be more specific, we compare in Table 1 the AWGs built on different platforms such as silica, polydimethylsiloxane, and $\mathrm{Si}_{3} \mathrm{~N}_{4}$ as suggested in our study. Notice that, in principle, $\mathrm{Si}_{3} \mathrm{~N}_{4}$-based AWGs can become superior in the spectroscopic applications. The reasons are as follows. First, $\mathrm{Si}_{3} \mathrm{~N}_{4}$ is a well-known dielectric transparent at the relatively short wavelengths in the visible and near-infrared ranges, and beyond. Second, it is a high index-contrast material with the effective index 1.9 in the visible range, which allows tight binding of waveguides and is very suitable for the integrated photonic circuits. And third, $\mathrm{Si}_{3} \mathrm{~N}_{4}$ is compatible with conventional complementary metal-oxide-semiconductor fabrication techniques [11-13, 17]. The remaining material is organizes as follows. The functional arrangement and the working principles of our AWGs are outlined in Section 2. The design strategy is described in Section 3. Subsequently, the simulation results are discussed in Section 4, followed by the main conclusions given in Section 5.

Table 1. Comparison of AWGs designed on different platforms.

\begin{tabular}{c|c|c|c|c}
\hline AWG Platform & $\begin{array}{c}\text { Propagation losses, } \\
\mathrm{dB} / \mathrm{cm}\end{array}$ & Size, $\mu \mathrm{m}^{2}$ & Footprint, $\mathrm{mm}^{2}$ & Cost \\
\hline $\begin{array}{c}\text { Silica strip waveguide } \\
{[13]}\end{array}$ & 0.4 & $3.0 \times 3.0$ & 130 & very high \\
\hline $\begin{array}{c}\text { Polydimethylsiloxane } \\
\text { rib waveguide [14] }\end{array}$ & 0.5 & $6.8 \times 8.0$ & 113 & low \\
\hline $\mathrm{Si}_{3} \mathrm{~N}_{4}$ strip waveguide & 0.1 & $0.5 \times 0.1$ & 0.2 & low \\
\hline
\end{tabular}

\section{Functional arrangement}

AWG represents an optical de/multiplexing device that consists of five main parts: an input waveguide, output waveguides, a free-propagation region 1 (abbreviated hereafter as FPR-1), a free-propagation region 2 (FPR-2), and a dispersive waveguide array (see Fig. 1). The input waveguide is connected with the dispersive waveguides via the FPR-1 block, while the dispersive waveguides are linked with the output waveguides via the FPR-2. The incoming light from a light source diffracts freely while passing through the FPR-1 and enters the array of waveguides. This array section is designed such that the optical path length difference between the adjacent waveguides equals to an integer multiple of the central wavelength.

When the diffracted light travels through the arrayed waveguides, a constant path length 


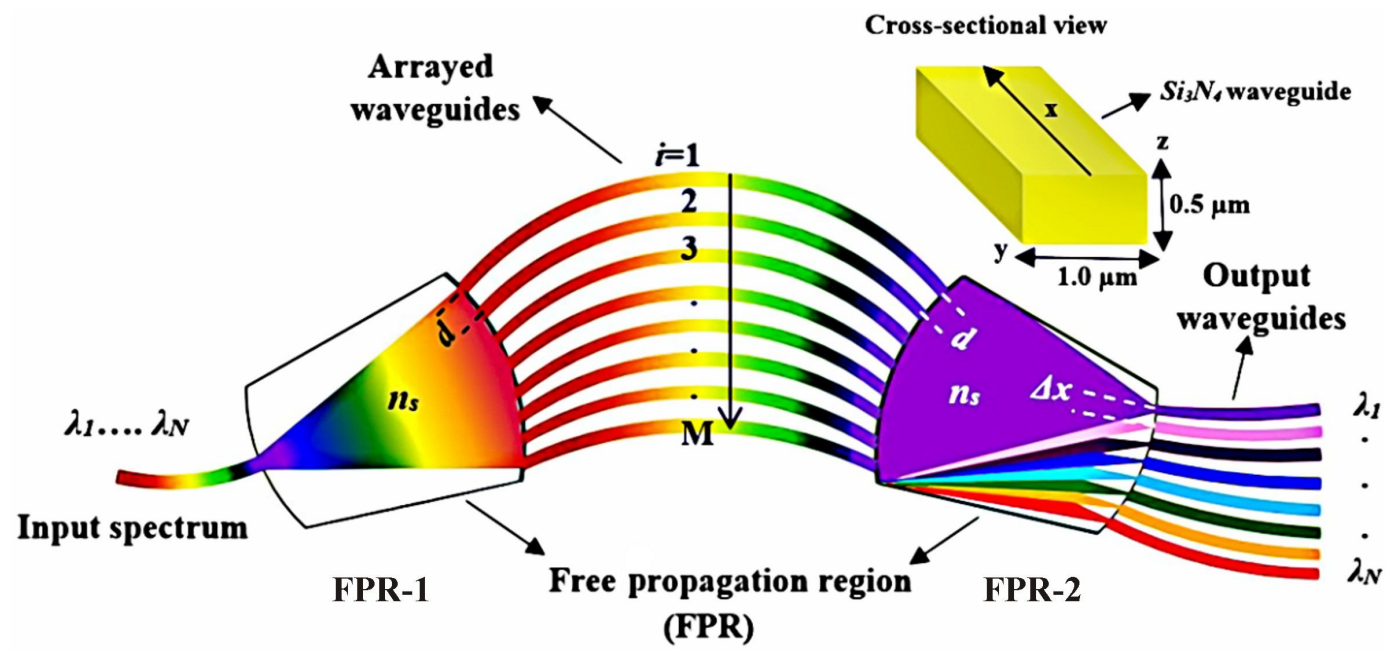

Fig. 1. A schematic diagram of our AWG suitable for the visible spectral range.

difference between the adjacent waveguides generates a constant phase delay. As a result, the field distribution at the input aperture is reproduced at the output aperture in the FPR-2. Therefore, the light is focused in the centre of the image plane just at the central wavelength. When the input wavelength detunes from the central wavelength, the focal point is shifted along the image plane. The separation of the wavelengths can be done by proper positioning the output waveguides along the image plane [15].

\section{Design strategy}

We have designed our AWGs using a single-mode silicon-nitride waveguide as a basic building block (see Ref. [18]). Finite-difference time-domain simulations of the single-mode silicon-nitride waveguide have been performed to determine the effective and group indices. These simulation results are necessary to further determine such design parameters of the AWGs as the optical path length difference and the focal lengths of the FPRs. We have determined the diffraction orders for the overall wavelength region $(400-800 \mathrm{~nm})$ after dividing the initial wavelength by the difference between the final and initial wavelengths. The constant optical path length difference between the adjacent waveguides has been calculated by dividing the product of the diffraction order and the central wavelength by the effective index of the core.

The focal lengths of the FPRs have been calculated by dividing the product of the effective indices and the pitch distances by the product of the diffraction order, the channel spacing and the group index. The number of array waveguides has been selected such that all of the diffracted light in the free-space region become sufficiently coupled to the array, thus forming a numerical aperture. The array waveguides have been designed to be four times larger than the number of wavelength channels, using a general 'rule of thumb'.

The mathematical expressions for the diffraction order $m$, the optical path length difference $\Delta L$, the focal length $L_{f}$ and the number $P$ of arrayed waveguides are as follows [19]:

$$
\begin{gathered}
m=\frac{\lambda_{1}}{\lambda_{N}-\lambda_{1}}, \\
\Delta L=\frac{m \lambda_{0}}{n_{c}},
\end{gathered}
$$




$$
\begin{aligned}
& L_{f}=\frac{n_{s} d \Delta x n_{c}}{m \Delta \lambda n_{g}}, \\
& P=4 N_{\text {max }}=4\left(\frac{F S R}{\lambda_{0}}\right)_{\text {integer }} .
\end{aligned}
$$

Here $\lambda_{1}$ and $\lambda_{N}$ are the starting and ending wavelengths of the region where the AWG can transmit the light, and $\lambda_{0}$ denotes the central wavelength. The latter is defined by peak-mode measurements of residing effective optical power or, alternatively, as the wavelength of the optical source that can be considered as a central one. Both of our AWGs work at the central wavelength $777 \mathrm{~nm}$, which is chosen since many optical sources are available at this wavelength. Furthermore, $\Delta \lambda$ means the wavelength channel spacing, $n_{c}$ and $n_{s}$ are the effective indices of respectively core and slab waveguides, $n_{g}$ is the group index, $d$ the pitch length of the arrayed aperture, and $\Delta x$ the pitch length of the input and output waveguides (see also Fig. 1 and Table 2). Finally, $N_{\max }$ represents the maximum number of wavelength channels, and the FSR the spacing in the optical frequency (or the wavelength) between the maxima or minima of interference pattern.

Table 2. Typical values of the basic design parameters used in our AWGs.

\begin{tabular}{cccc}
\hline Parameter & $\begin{array}{c}\text { Notation of the } \\
\text { parameter }\end{array}$ & First AWG & Second AWG \\
\hline Central wavelength, $\mathrm{nm}$ & $\lambda_{0}$ & 777 & 777 \\
Channel spacing, nm & $\Delta \lambda$ & 70 & 50 \\
Number of channels & $N$ & 5 & 8 \\
Diffraction order & $m$ & 1 & 1 \\
Array waveguides & $P$ & 25 & 37 \\
Length difference, $\mu \mathrm{m}$ & $\Delta L$ & 0.41 & 0.41 \\
Slab refractive index & $n_{s}$ & 1.87 & 1.87 \\
Effective refractive index & $n_{c}$ & 1.90 & 1.90 \\
Group refractive index & $n_{g}$ & 2 & 2 \\
Array pitch length, $\mu \mathrm{m}$ & $d$ & 1.45 & 1.42 \\
Output waveguide pitch, $\mu \mathrm{m}$ & $\Delta x$ & 3.78 & 6.68 \\
Focal length, $\mu \mathrm{m}$ & $L_{f}$ & 108 & 312 \\
Chip size, $\mathrm{mm}^{2}$ & $A$ & 0.02 & 0.20 \\
\hline
\end{tabular}

The typical values of our design parameters for the two our AWGs, referred hereafter to as the 'first' and 'second' AWGs, are listed in Table 2. The first AWG is very compact. It includes 25 closely packed arrayed waveguides and two FPRs with the focal lengths equal to $108 \mu \mathrm{m}$. Its array pitch amounts to $1.45 \mu \mathrm{m}$ and the output-waveguide pitch to $3.78 \mu \mathrm{m}$. These parameters result in an AWG which has five output channels that cover the region $400-800 \mathrm{~nm}$ and is characterized with the bandwidth $15 \mathrm{~nm}$, as measured at the level of $3 \mathrm{~dB}$. The overall size of the device is only $0.02 \mathrm{~mm}^{2}$, which is much smaller than that typical for a comparable silica-based device reported recently in Ref. [15 13].

To design an AWG suitable for the broad enough visible region and high spectral resolution, one should require increasing interference order of the grating or increasing number of the arrayed waveguides. Moreover, one has to narrow the pitch lengths of the input and output apertures, increase the focal length of the FPRs and the diffraction order, as well as employ tapered arrayed waveguides, until a desired resolution is achieved. In particular, enlarging the array section or using the waveguides with extremely high group indices can be helpful for increasing the grating 
order of any AWG-based spectrometer [8]. However, increasing the grating order can reduce the free spectral range and so limit the bandwidth of the AWG. In order to maintain a small footprint and a wide operational bandwidth, it would be advantageous to use minimal input and output aperture lengths. Notice also that the array-pitch length cannot be reduced to dimensions smaller than a critical length, which is constrained by the critical dimensions of the mask used in the fabrication process [15].

In our case, we set the latter parameter to be equal to $1.45 \mu \mathrm{m}$, which allows the separation $0.45 \mu \mathrm{m}$ between the adjacent waveguides. Then the minimal possible waveguide separation is close to $0.4 \mu \mathrm{m}$. The diffraction order $m$ is equal to unity for the wavelength region $400-800 \mathrm{~nm}$. Since $\Delta L$ is directly related to the diffraction order, which implies a low diffraction order, one obtains lower path length differences and so lower wavelength resolutions. We mention in this respect that conventional AWGs are usually designed for narrow enough spectral bands, because the diffraction order is relatively high for the small-wavelength regions, thus resulting in high resolutions.

To address these problems, we have changed significantly the design of our second AWG. Namely, the focal length is increased up to $312 \mu \mathrm{m}$, the array section is enlarged (i.e., the number of arrayed waveguides is increased up to 37), and the array-pitch distance is reduced down to $1.42 \mu \mathrm{m}$. As a result, we have successfully achieved the $3 \mathrm{~dB}$ bandwidth $4 \mathrm{~nm}$, while the insertion losses have remained small enough $(7.56 \mathrm{~dB} / \mathrm{cm})$ at the central wavelength of $777 \mathrm{~nm}$. The transmission spectra of our AWGs are discussed in the next section.

\section{Results and discussion}

Simulations for the both of our AWGs have been performed using a 2.5D var-finite-difference time-domain method, which is provided by Lumerical Mode Solution. To reduce computational costs, we have broken the device into three sections (the FPR-1, the array waveguides and the FPR-2) arranged in cascade. A combination of sources, field monitors and mode-expansion monitors has been used to analyze the fraction of optical power transmitted into fundamental mode of the output waveguides. In frame of the var-finite-difference time-domain method, this combination can also be used to extract the scattering parameters, which are known also as reflection and transmission coefficients. This provides an interface between the component-level and circuit-level simulations which involve multiple components in arbitrarily complex configurations.

A mode/light source has been used to launch a fundamental mode along the input waveguide. The input waveguide mode spreads out in the FPR-1 and becomes distributed among different output array waveguides. The mode-expansion monitors and the transmission monitors have been set up at each output array waveguide to determine how much power is actually transmitted into the fundamental mode of the output waveguides. The distribution of incoming light among different waveguides defines the percentage forward light transmission into each waveguide. It depends mostly on the length of the FPR-1 and the number of the waveguides. For instance, light spreads out in the FPR-1 with the focal length $108 \mu \mathrm{m}$ and gets distributes among 25 waveguides in our first AWG.

As seen from Fig. 2a, some 1.5-2.0\% of the incoming light suffers forward transmission into each waveguide. The data shown in Fig. $2 \mathrm{~b}$ testifies that less than $1 \%$ of the incoming light is forward-transmitted in our second AWG. This is because of higher length of the FPR-1 $(312 \mu \mathrm{m})$ and increased number of waveguides that equals to 37 . Of course, the total transmission, which is 
given by integration of the Poynting vector along the monitor plane, is greater than the forward transmission in the both cases. In other words, it is very easy to overestimate the true light transmission in terms of the total transmission. This is why, we have performed the modeexpansion calculations to determine the actual optical transmission, instead of simply looking at the total transmission.
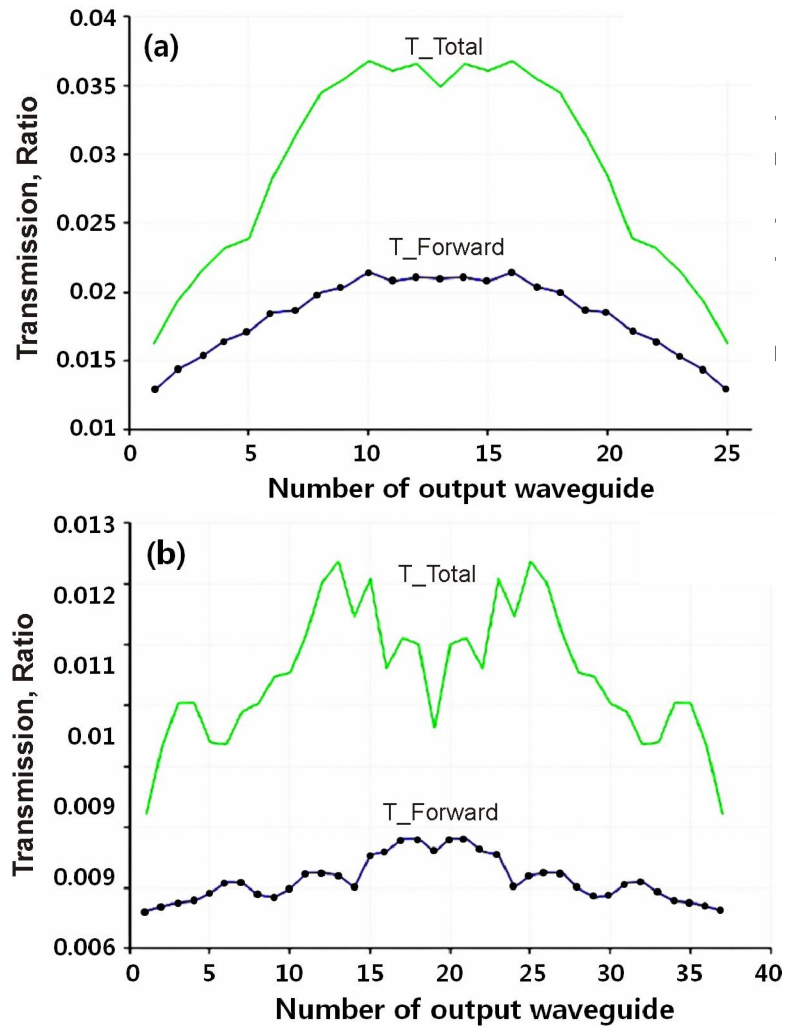

Fig. 2. Results of simulations of the FPR-1 as obtained for (a) the first AWG and (b) the second AWG.

The array section is designed such that the optical path length difference $\Delta L$ between any of the successive waveguides remains constant. Consequently, the phase change $\Delta \varphi$ across each successive channel is also constant, which corresponds to the time delay $\Delta t=\Delta L / V_{g}$ between the channels, with $V_{g}$ being the group velocity at which the overall optical wave propagates through the waveguide. This means that, in order to get the correct phase difference in the time-domain simulations, one has to set this time delay for each of the input modes of the FPR-2.

Once the light enters the FPR-2, it is refocused at one of the output waveguides. A frequencydomain field monitor has been set up to enable finding the profiles of the electric field (or simply $E$-field) along the plane $X Y$ of the FPR-2. The raw electric-field data inside the monitor is distributed among several matrices, then each of the vector field components $\left(E_{x}, E_{y}\right.$ and $\left.E_{z}\right)$ is stored in the matrix and, finally, the corresponding position vectors $(x, y, z$ and the frequency/wavelength) are stored as separate 4D matrices. All of this information is then stored as a single dataset variable, which is further used by the visualizer to select a slice out of the matrix and to plot a 2D image of the $E$-field at different wavelengths. Fig. 3 show the $E$-field profiles for the FPR-2 at different wavelengths for our second AWG. Here the $X$ and $Y$ axes correspond to the magnitudes of respectively $x$ - and $y$-position vectors, while the colour-bar scale visualizes the 
normalized $E$-field intensity, which is scaled from minimum to maximum using dark blue and dark red colours, respectively.

As the source wavelength changes from shorter to longer wavelengths, the focal points move along the right edge of the FPR-2, thus coupling into different output waveguides depending on the wavelength. This de-multiplexing functionality is the outcome of the phase difference from the time delay we have earlier specified.
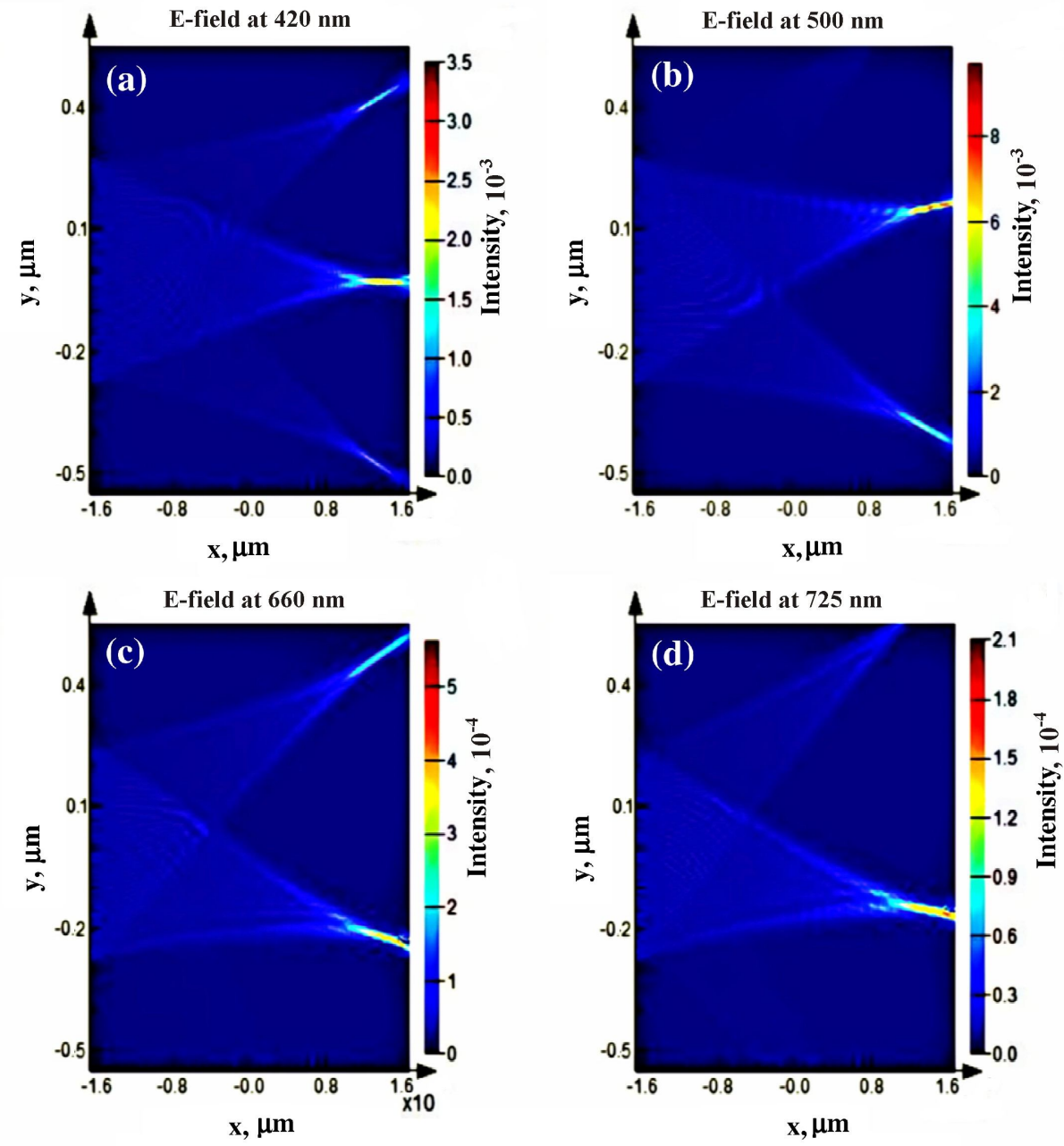

Fig. 3. E-field profiles calculated for the FPR-2 in case of the second AWG, as measured at different wavelengths: (a) 420, (b) 500, (c) 660 and (d) $725 \mathrm{~nm}$.

The corresponding transfer function calculated for the first AWG is depicted in Fig. 4. The five output channels with the maximal bandwidth $15 \mathrm{~nm}$, as defined at the level of $3 \mathrm{~dB}$, cover the whole visible spectral range. The overall optical transmission is larger than $35 \%$, with the maximum $45 \%$ achieved in the channel \#5. The free spectral range is about $777 \mathrm{~nm}$ because of the wide operational wavelength region. The channel spacing is close to $70 \mathrm{~nm}$, while the adjacentchannel cross-talk is less than $-25 \mathrm{~dB}$ around $460 \mathrm{~nm}$.

The optical transmission spectra for the second AWG (see Fig. 5) demonstrate efficiency of our idea of increasing the focal length and decreasing the pitch size of the array aperture. The $3 \mathrm{~dB}$ bandwidth is now improved up to the maximal value of $4 \mathrm{~nm}$. Notice also that the $\mathrm{Si}_{3} \mathrm{~N}_{4}$-based 


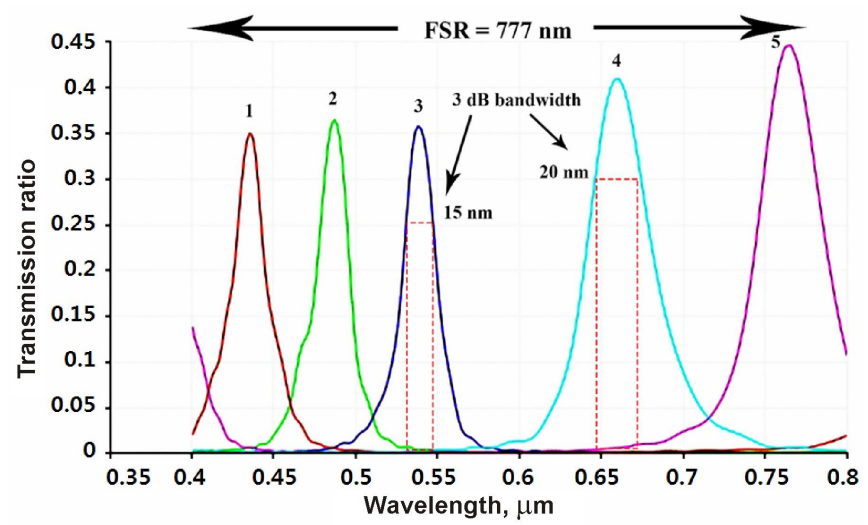

Fig. 4. Optical transmission spectra calculated for the first AWG with the maximal bandwidth $15 \mathrm{~nm}$ defined at the level of $3 \mathrm{~dB}$ (see the text).

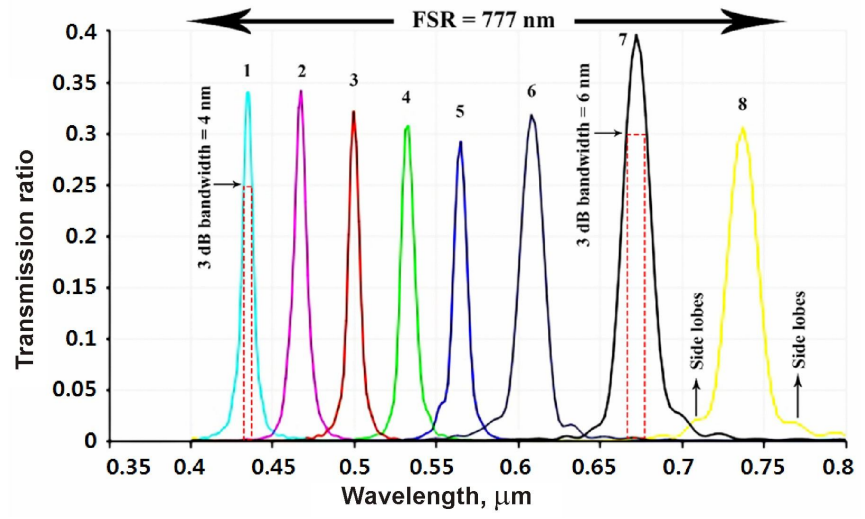

Fig. 5. Optical transmission spectra calculated for the second AWG with the maximum bandwidth $4 \mathrm{~nm}$ defined at the level $3 \mathrm{~dB}$ (see the text).

waveguides reveal stronger optical confinement for shorter wavelengths, thus reducing the coupling between the adjacent waveguides. Therefore, the side lobes in the spectrum become smaller and, hence, the output channels become sharper. One can also see that the spectral resolution for the shorter-wavelength channels is higher than that for the longer-wavelength ones. The channel \#1 has the maximal spectral resolution $4 \mathrm{~nm}$ at the $3 \mathrm{~dB}$ level, and the resolution decreases gradually for the longer-wavelength channels. The overall optical transmission is around $30 \%$, which is $5 \%$ less than that obtained for the first AWG, while the maximal transmission reached in the channel $\# 7$ amounts to $40 \%$. The free spectral range is equal to the same value as before $(777 \mathrm{~nm})$ because of the same operational wavelength. The channel spacing is about $50 \mathrm{~nm}$ for the eight output channels. Finally, the adjacent-channel cross-talk is less than $-30 \mathrm{~dB}$ around $450 \mathrm{~nm}$. Notice that the insertion losses are $7.56 \mathrm{~dB} / \mathrm{cm}$ for the both AWGs designed by us.

\section{Conclusion}

Summing up, we have designed and simulated the work of the two AWGs suited for the visible spectral range $(400-800 \mathrm{~nm})$. The AWGs suggested by us are based on a single-mode siliconnitride waveguide, which reveals a small propagation loss $(0.1 \mathrm{~dB} / \mathrm{cm})$ and a very small bending loss $0.1 \mathrm{~dB} / \mathrm{cm}$ at the bending angle $90^{\circ}$. This idea, which has earlier been reported by the authors in Ref. [18], has proved to be useful for the visible spectral range. While, in its earlier design, our 
AWG has shown the maximum bandwidth $15 \mathrm{~nm}$ defined at the level of $3 \mathrm{~dB}$ [18], the resolution in its present design has been greatly improved by increasing the focal length of slab regions and the number of arrayed waveguides. Moreover, a decrease in the pitch size of the array aperture has enabled us to successfully achieve the maximal $3 \mathrm{~dB}$ bandwidth $4 \mathrm{~nm}$, while the insertion loss at the transmission-spectrum peak has remained the same, $7.56 \mathrm{~dB} / \mathrm{cm}$. As a consequence, small footprint, high resolution, low insertion losses and ability to work in a broad visible spectral range make our device suitable for diverse on-chip applications, e.g. for rapid in-situ monitoring and real-time diagnostics in engineering applications.

\section{Acknowledgement}

This work has been supported by the Advanced Research Group at Myongji Phonics Electronics Embedded System through Myongji University Research Fund (2017).

\section{References}

1. Takahashi H, Suzuki S, Kato K and Nishi I, 1990. Arrayed-waveguide grating for wavelength division multi/demultiplexer with nanometre resolution. Electron. Lett. 26: 87-88.

2. Dragone C, 1991. An $\mathrm{N}^{*} \mathrm{~N}$ optical multiplexer using a planar arrangement of two-star couplers. EEE Photon. Technol. Lett. 3: 812-815.

3. Ryckeboer E, Gassenq A, Muneeb M, Hattasan N, Pathak S, Cerutti L, Rodriguez J B, Tournié E, Bogaerts W, Baets R and Roelkens G, 2013. Silicon-on-insulator spectrometers with integrated GaInAsSb photodiodes for wide-band spectroscopy from 1510 to $2300 \mathrm{~nm}$. Opt. Express. 21: 6101-6108.

4. Piels M, Bauters J F, Davenport M L, Heck M J and Bowers J E, 2014. Low-loss silicon nitride AWG demultiplexer heterogeneously integrated with hybrid III-V/silicon photodetectors. J. Lightwave Technol. 32: 817-823.

5. Kodate $\mathrm{K}$ and Komai $\mathrm{Y}, 2008$. Compact spectroscopic sensor using an arrayed waveguide grating. J. Optics A: Pure Appl. Opt. 10: 044011.

6. Gatkine P, Veilleux S, Hu Y., Bland-Hawthorn J and Dagenais M, 2017. Arrayed waveguide grating spectrometers for astronomical applications: new results. Opt. Express. 25: 1791817935.

7. Barbarin Y, Lefrançois A, Magne S, Chuzeville V, Balbarie M, Jacquet L, Sinatti F, Osmont A and Luc J, 2017, Dynamic measurements of physical quantities in extreme environment using fiber Bragg grating. In: 25th Optical Fiber Sensors IEEE Conference, 2017. pp. 1-4.

8. Cheben P, Schmid J H, Delâge A, Densmore A, Janz S, Lamontagne B, Lapointe J, Post E, Waldron P and Xu D X, 2007. A high-resolution silicon-on-insulator arrayed waveguide rating microspectrometer with sub-micrometer aperture waveguides. Opt. Express. 15: 22992306.

9. Okamoto K, Moriwaki K and Suzuki S, 1995. Fabrication of $64 * 64$ arrayed-waveguide grating multiplexer on silicon. Electron. Lett. 31: 184-186.

10. Diemeer J, Ramsamoedj R and Smit K, 1996. Polymeric phased array wavelength multiplexer operating around $1550 \mathrm{~nm}$. Electron. Lett. 32: 1132-1133.

11. Martens D, Subramanian A Z, Pathak S, Vanslembrouck M, Bienstman P, Bogaerts W and Baets R, 2015. Compact silicon nitride arrayed waveguide gratings for very near-infrared wavelengths. IEEE Photon. Technol. Lett. 27: 137-140.

12. Rahim A, Ryckeboer E, Subramanian A Z, Clemmen S, Kuyken B, Dhakal A, Raza A, Hermans A, Muneeb M, Dhoore S and Li Y, 2017. Expanding the silicon photonics portfolio 
with silicon nitride photonic integrated circuits. J. Lightwave Technol. 35: 639-649.

13. Suzuki K, Hida Y, Shibata T, Inoue Y, Takahashi H and Okamoto K, 2006. Silica-based arrayed-waveguide gratings for the visible wavelength range. NTT Tech. Rev. 4: 48-52.

14. Poenar D P, Kee J S, Neuzil P and Yobas L, 2009. The design and fabrication of poly (dimethylsiloxane) single mode rib waveguides for lab-on-a-chip applications. In: Advanced Materi-als Research (Trans Tech Publications). 74: 51-54.

15. Kee J S, Poenar D P, Neužil P, Yobaş L and Chen Y, 2010. Design and fabrication of Poly (di-methylsiloxane) arrayed waveguide grating. Opt. Express. 18: 21732-21742.

16. Hwang S, Lee M, Kim S and Hong S, 2017. Characterization of silicon nitride-cored silicon photonics waveguide material for optical microring resonator. J. Nanoelectron. Optoelectron. (at press).

17. Stanton E J, Spott A, Davenport M L, Volet N and Bowers J E, 2016, June. Arrayed waveguide grating near $760 \mathrm{~nm}$ wavelength for integrated spectral beam combining applications. In: La-sers and Electro-Optics IEEE Conference, 2016. pp. 1-2.

18. Hwang S, Lee M, Kim S and Hong S, 2017. Characterization of silicon nitride-cored silicon photonics waveguide material for optical microring resonator. J. Nanoelectron. Optoelectron. (at press).

19. Elndash A, Mohammed N A, Rashed A N Z, Elndash A and Saad F A, 2009. Estimated optimization parameters of arrayed waveguide grating (AWG) for C-band applications. Int. J. Phys. Sci. 4: 149-155.

Syed Ashar Ali and Sang Jeen Hong. 2017. Compact arrayed waveguide gratings for visible wavelengths based on silicon nitride. Ukr.J.Phys.Opt. 18: 239 - 248.

Анотація. Ми представили дві кремнієво-нітридові хвилеводні гратки (XI), які працюють у широкому видимому діапазоні довжин хвиль 400-800 нм на иентральній довжині хвилі 777 нм. XI із серцевинами $\mathrm{Si}_{3} \mathrm{~N}_{4}$ сконструйовано так, аби забезпечити характеристики одномодового режиму хвилеводу. Вони виявляють типові втрати поширення 0,1 дБ/см $i$ втрати на згинах 0,1 дБ при куті згину 90. Одна з наших ХI забезпечуе п'ять каналів із шириною смуги пропускання 15 нм на рівні 3 дБ, а інша - вісім каналів із поліпшеною смугою пропускання 4 нм на рівні 3 дБ. Втрати на введення для обох ХІ дорівнюють 7,56 Б/см на піку спектра пропускання. Крім того, наші ХІ виявляють хороші спектральні характеристики $i$ досить малі розміри $\left(0,02\right.$ i 0,20 мм $^{2}$ відповідно для $n$ 'яти- та восьмиканальної ХI). 